\title{
Are TKAs Performed in High-volume Hospitals Less Likely to Undergo Revision Than TKAs Performed in Low-volume Hospitals?
}

\author{
Elke Jeschke PhD, Mustafa Citak MD, PhD, Christian Günster, \\ Andreas Matthias Halder MD, Karl-Dieter Heller MD, Jürgen Malzahn MD, \\ Fritz Uwe Niethard MD, Peter Schräder MD, Josef Zacher MD, \\ Thorsten Gehrke MD
}

Received: 7 December 2016/ Accepted: 31 July 2017/Published online: 11 August 2017

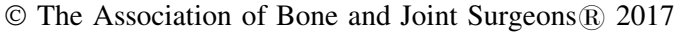

\begin{abstract}
Background High-volume hospitals have achieved better outcomes for THAs and unicompartmental knee arthroplasties (UKAs). However, few studies have analyzed implant survival after primary TKA in high-volume centers.

Questions/Purposes Is the risk of revision surgery higher when receiving a TKA in a low-volume hospital than in a high-volume hospital?

Methods Using nationwide billing data of the largest German healthcare insurer for inpatient hospital treatment,
\end{abstract}

Each author certifies that neither he or she, nor any member of his or her immediate family, have funding or commercial associations (consultancies, stock ownership, equity interest, patent/licensing arrangements, etc) that might pose a conflict of interest in connection with the submitted article.

All ICMJE Conflict of Interest Forms for authors and Clinical Orthopaedics and Related Research ${ }^{\mathbb{R}}$ editors and board members are on file with the publication and can be viewed on request.

This study was performed at the Research Institute of the Local Health Care Funds (Berlin, Germany).

E. Jeschke, C. Günster

Research Institute of the Local Health Care Funds (AOK), Berlin, Germany

M. Citak ( $\bowtie)$, T. Gehrke

Department of Orthopaedic Surgery, HELIOS ENDO-Klinik

Hamburg, Holstenstraße 2, 22767 Hamburg, Germany

e-mail: dr.mustafa.citak@gmail.com

A. Matthias Halder

Department of Orthopaedic Surgery, Sana Kliniken Sommerfeld,

Sommerfeld, Germany

K.-D. Heller

Department of Orthopaedic Surgery, Herzogin Elisabeth

Hospital, Braunschweig, Germany we identified 45,165 TKAs in 44,465 patients insured by Allgemeine Ortskrankenkasse who had undergone knee replacement surgery between January 2012 and December 2012. Revision rates were calculated at 1 and 2 years in all knees. The hospital volume was calculated using volume quintiles of the number of all knee arthroplasties performed in each center. We used multiple logistic regression to model the odds of revision surgery as a function of hospital volume. Age, sex, 31 comorbidities, and variables for socioeconomic status were included as independent variables in the model.

Results After controlling for socioeconomic factors, patient age, sex, and comorbidities, we found that having surgery in a high-volume hospital was associated with a decreased risk of having revision TKA within 2 years of the index procedure. The odds ratio for the 2-year revision was $1.6(95 \% \mathrm{CI}, 1.4-2.0 ; \mathrm{p}<0.001)$ for an annual hospital volume of 56 or fewer cases, 1.5 (95\% CI, 1.3-1.7; p < 0.001 ) for 57 to 93 cases, 1.2 (95\% CI, 1.0-1.3; p = 0.039) for 94 to 144 cases, and $1.1(95 \% \mathrm{CI}, 0.9-1.2 ; \mathrm{p}=0.319)$

\author{
J. Malzahn \\ Federal Association of the Local Health Care Funds, Berlin, \\ Germany \\ F. U. Niethard \\ German Society of Orthopedics and Orthopedic Surgery, Berlin, \\ Germany \\ P. Schräder \\ Department of Orthopaedic Surgery, Kreisklinik Jugenheim, \\ Jugenheim, Germany \\ J. Zacher \\ HELIOS Kliniken GmbH, Berlin, Germany
}


for 145 to 251 cases compared with a hospital volume of 252 or more cases.

Conclusions We found a clear association of higher risk for revision surgery when undergoing a TKA in a hospital where less than 145 arthroplasties per year were performed. The study results could help practitioners to guide potential patients in hospitals that perform more TKAs to reduce the overall revision and complication rates. Furthermore, this study underscores the importance of a minimum hospital threshold of arthroplasty cases per year to get permission to perform an arthroplasty.

Level of Evidence Level III, therapeutic study.

\section{Introduction}

The number of TKAs will increase dramatically during the next decade [13, 15]. To improve patient outcomes, it is imperative to identify the factors that influence surgical results. In this context, hospital volume has been proposed as one of the best indicators of patient outcomes in hip replacement surgery [26]. This also has been reported for unicompartmental knee arthroplasties (UKAs) with lowvolume hospitals being unambiguously associated with a higher risk for revision surgery [2, 3, 9].

Some studies have analyzed the influence of length of stay, readmission, and mortality rates at 30 or 90 days after TKA $[11,14,16,17,19,20,23,25,27,28]$. The effect of hospital volume on revision rates after TKA also has been reported [4, 6, 8, 17, 18, 24]. Most of the prior studies have had results based on Medicare or other nationwide inpatient samples. Despite the large number of patients included in these studies, the data lack detailed information regarding clinically important characteristics.

In the current investigation, we used the German insurance claims database to address these shortcomings and to evaluate the following research question: Are TKAs performed in high-volume hospitals less likely to undergo revision than TKAs performed in low-volume hospitals? The main advantages of the German insurance database is the completeness of the data and there is no bias from the exclusion of certain patient groups. Furthermore, patient factors that could influence the risk of revision are included.

\section{Materials and Methods}

\section{Study Sample and Data Collection}

Data were collected from the German healthcare insurance Allgemeine Ortskrankenkasse (AOK). The AOK provides nationwide healthcare insurance for approximately $30 \%$ of the German population and is the largest provider of statutory healthcare insurance in Germany. Everyone is allowed to enroll in the AOK regardless of factors such as age, preexisting comorbidities, income, or type of employment. The data were derived from billing data for inpatient hospital treatment. They comprise a unique identification number, age, sex, side, main diagnosis and comorbidities, procedures, length of stay, patient survival, and insurance status. Diagnoses were coded according to the 10th revision of the International Classification of Diseases (ICD-10). Procedures were documented using the German version of the International Classification of Procedures in Medicine, the OPS. Data from the federal institute for urban construction and space exploration were used to estimate household income and educational levels based on the patient's residential zip code.

All AOK-insured patients older than 20 years who had undergone a TKA (OPS "5-822.1X/2X/3X/4X, 5-822.aX/ bX, 5-822.dX/eX") between January 2012 and December 2012 for diagnoses of arthritis (M17), osteonecrosis (M87), or rheumatoid arthritis of the knee (M05-M08) were identified and initially included in the study. Replacement surgeries in both knees during the study period were counted as two separate TKAs. Patients were excluded from the study if they met any of the following criteria: had a diagnosis of posttraumatic arthritis of the knee (M17.2, M17.3); had any surgery of the knee 2 years before knee replacement surgery; or had a diagnosis of tumor diseases, osteoporosis, or bone cysts.

A total of 45,165 TKAs treated in 966 hospitals were included in the final analysis (Table 1). Sixty-eight percent of the patients were women $(30,698$ of 45,165 patients). Seventy-two percent were between 60 and 79 years old (32,564 of 45,165 patients), while only $2 \%$ were younger than 50 years (906 of 45,165 patients) (Table 2). The most common diagnosis for knee replacement surgery was osteoarthritis with $100 \%$ (45,042 of 45,165 patients). Hypertension, obesity, and diabetes mellitus were the most common concomitant diseases (Table 3). The median unemployment rate was $7 \%(\mathrm{SD}, \pm 3)$ and the median percentage of people with an academic status was $12 \%$ (SD, \pm 4$)$.

Healthcare providers and healthcare insurances jointly issue binding guidelines for coding of diagnoses and procedures in hospital claims. Hospital claims data in Germany are thoroughly checked against these guidelines and for plausibility by the Medical Review Board of the Statutory Health Insurance Funds and are returned to hospitals for correction if necessary. Corrections are included in the claims data used in this analysis. 
Table 1. Detailed information regarding hospital treatment frequencies in 2012

\begin{tabular}{|c|c|c|c|c|c|c|}
\hline \multirow[t]{2}{*}{ Hospital treatment } & \multirow[t]{2}{*}{ Total } & \multicolumn{5}{|c|}{ Volume quintile } \\
\hline & & 1 & 2 & 3 & 4 & 5 \\
\hline $\begin{array}{l}\text { Number of TKAs per hospital* } \\
\quad \text { (minimum-maximum) }\end{array}$ & $10-1.648$ & $10-56$ & $57-93$ & $94-144$ & $145-251$ & $252-1.648$ \\
\hline $\begin{array}{l}\text { Number of TKAs per hospital* } \\
\text { (median; IQR) }\end{array}$ & $113(66-218)$ & $40(24-49)$ & $75(66-84)$ & $115(102-130)$ & $190(163-218)$ & $404(319-547)$ \\
\hline Number of included hospitals (\%) & $966(100)$ & $197(20)$ & $194(20)$ & $192(20)$ & $190(20)$ & $193(20)$ \\
\hline $\begin{array}{l}\text { Number of recruited AOK- } \\
\text { patients }(\%)\end{array}$ & $45,165(100)$ & $2,689(6)$ & $4,513(10)$ & $7,442(17)$ & $10,344(23)$ & $20,177(45)$ \\
\hline
\end{tabular}

*All insured patients, data of external stationary quality assurance (AQUA 2012), IQR = interquartile range; AOK = Allgemeine Ortskrankenkasse.

Table 2. Age and sex distribution of patients with AOK versus those from the stationary quality assurance data*

\begin{tabular}{|c|c|c|c|c|}
\hline \multirow[t]{2}{*}{ Variable } & \multicolumn{2}{|c|}{ AOK patients 2012} & \multicolumn{2}{|c|}{ Germany $2012 *$} \\
\hline & Number & $\%$ & Number & $\%$ \\
\hline Number & 45,165 & 100 & 133,777 & 100 \\
\hline \multicolumn{5}{|l|}{ Age } \\
\hline$<50$ years & 906 & 2 & 3422 & 3 \\
\hline $50-59$ years & 5708 & 13 & 17,979 & 13 \\
\hline $60-69$ years & 11,777 & 26 & 37,355 & 28 \\
\hline 70-79 years & 20,787 & 46 & 58,628 & 44 \\
\hline $80-89$ years & 5804 & 13 & 16,047 & 12 \\
\hline$\geq 90$ years & 105 & 0 & 346 & 0 \\
\hline \multicolumn{5}{|l|}{ Sex } \\
\hline Female & 30,698 & 68 & 87,162 & 65 \\
\hline Number of hospitals & 966 & & 1033 & \\
\hline
\end{tabular}

*Data of external stationary quality assurance (AQUA 2012).

\section{Study Outcomes}

The primary outcome measure was revision surgery within 2 years after primary implantation. Revision rates were calculated at 1 and 2 years in all knees. A total of 1596 (3.5\%) patients who had TKAs were lost to followup at the latest followup, while 1199 of the 1596 patients are deceased. Revision surgery was defined as removal or exchange of at least one implant component on the surgically treated knee. Secondary patella resurfacing and polyethylene changes also were counted as failures. Any soft tissue disorder requiring a revision surgery with open or arthroscopic débridement and/or irrigation also was noted as failure 31 days after the index surgery.

Revision after knee replacement surgery was modeled as a function of hospital volume. The hospital volume was calculated using volume quintiles of the number of all knee arthroplasties performed in each center. The data were taken from the stationary quality assurance data from 2012 [1].

On this basis, hospitals were classified in five groups: 1 st quintile: 10 to 56 cases per year; 2 nd quintile: 57 to 93
Table 3. Overview of indication and concomitant diseases

\begin{tabular}{llr}
\hline & Number & $\%$ \\
\hline Variable & 45,165 & 100 \\
Diagnosis & & \\
Gonarthrosis & 45,042 & 100 \\
Osteonecrosis & 82 & 0 \\
Rheumatoid arthritis & 41 & 0 \\
Concomitant diseases (sorted by frequency)* & \\
Hypertension & 31,508 & 67 \\
Obesity & 11,130 & 25 \\
Diabetes mellitus & 9946 & 22 \\
Cardiac arrhythmia & 4832 & 11 \\
Fluid and electrolyte disorders & 4586 & 10 \\
Chronic pulmonary disease & 3529 & 8 \\
Congestive heart failure & 3251 & 7 \\
Renal failure & 3133 & 7 \\
Depression & 2219 & 5 \\
Rheumatic disease & 1201 & 3 \\
Peripheral vascular disorders & 1011 & 2 \\
Valvular disease & 1010 & 2 \\
Neurologic disorders & 901 & 2 \\
\hline
\end{tabular}

*Double entries possible; sorted by descending frequency; other analyzed comorbidities with frequency $<2 \%$ are not shown (pulmonary circulation disorders, liver disease, coagulopathy, blood loss anemia, deficiency anemia, hypothyroidism, peptic ulcer disease excluding bleeding, weight loss, paralysis, alcohol abuse, drug abuse, psychoses, AIDS/HIV).

cases per year; 3rd quintile: 93 to 144 cases per year, 4 th quintile: 145 to 251 cases per year; and 5th quintile: 252 to 1648 cases per year (Table 1).

According to our classification method, 20,177 cases (45\%) were treated in high-volume hospitals $(>252$ cases per year), while 7202 cases (16\%) were treated in low-volume hospitals $(<93$ cases per year) (Table 1$)$. The German claims database does not provide information regarding surgeon volume. Therefore, the effect of surgeon volume on surgical outcomes was not included in the final analysis. 
Table 4. Revision rates after primary implantation for the different hospital volumes

\begin{tabular}{|c|c|c|c|c|c|c|c|}
\hline \multirow[t]{3}{*}{ Indicator } & \multirow{3}{*}{$\begin{array}{l}\text { Analyzed } \\
\text { cases* } \\
\text { Number }\end{array}$} & \multirow{3}{*}{$\begin{array}{l}\text { Total } \\
\%\end{array}$} & \multicolumn{5}{|c|}{ Volume quintile } \\
\hline & & & 1 & 2 & 3 & 4 & 5 \\
\hline & & & $\%$ & $\%$ & $\%$ & $\%$ & $\%$ \\
\hline Revision within 1 year & 44,238 & 3.7 & 5.2 & 4.3 & 3.8 & 3.5 & 3.3 \\
\hline Revision within 2 years & 43,569 & 5.5 & 7.5 & 6.7 & 5.8 & 5.2 & 4.9 \\
\hline
\end{tabular}

*Censoring considered.

Table 5. Results of multivariable logistic regression analysis for independent risk factors for revision within 2 years after TKA

\begin{tabular}{lll}
\hline Variable & \multicolumn{2}{l}{ Logistic regression analysis* } \\
\cline { 2 - 3 } & $\begin{array}{l}\text { Adjusted odds ratio } \\
\text { (95\% CI) }\end{array}$ & $\mathrm{p}$ Value \\
\hline Female sex & $0.9(0.8-1.0)$ & 0.011 \\
Age (years) & $0.97(0.97-0.98)$ & $<0.001$ \\
Comorbidities & & \\
Obesity with BMI $\geq 40 \mathrm{~kg} / \mathrm{m}^{2}$ & $1.4(1.1-1.8)$ & 0.005 \\
Fluid and electrolyte disorders & $1.2(1.0-1.4)$ & 0.015 \\
Chronic pulmonary disease & $1.2(1.0-1.4)$ & 0.031 \\
Congestive heart failure & $1.3(1.1-1.5)$ & 0.005 \\
Depression & $1.4(1.2-1.7)$ & $<0.001$ \\
Peripheral vascular disorders & $1.6(1.2-2.1)$ & 0.002 \\
Neurologic disorders & $1.6(1.2-2.1)$ & 0.002 \\
Alcohol abuse & $2.2(1.2-4.1)$ & 0.013 \\
Annual hospital volume & & $<0.001$ \\
1 (10-56 cases) & $1.6(1.4-2.0)$ & $<0.001$ \\
2 (57-93 cases) & $1.5(1.3-1.7)$ & 0.039 \\
3 (94-144 cases) & $1.2(1.0-1.3)$ & 0.319 \\
4 (145-251 cases) & $1.1(0.9-1.2)$ & \\
5 (252-1648 cases) & Reference & \\
\hline
\end{tabular}

*Logistic regression model adjusted for patient age, sex, primary diagnosis (gonarthrosis versus other), comorbidity, variables for socioeconomic status (eg, unemployment rate, academic status, household income), and hospital volume; only significant results are shown.

\section{Statistical Analysis}

We used multiple logistic regression to model the odds of revision surgery as a function of hospital volume. Age, sex, primary diagnosis (osteoarthritis versus other), variables for socioeconomic status (eg, unemployment rate, academic status, household income) and comorbidities were included as independent variables in the model. Comorbidities were defined using the Elixhauser measure developed in 1998 to predict mortality from administrative data [7]. The definition includes 31 acute and chronic comorbidities. Comorbidities were identified using the coding algorithm by Quan et al. [22] based on the ICD-10 coding (for example, diabetes [E10-E14], depression [F20.4, F31.3-F31.5, F32.X, F33.X, F34.1, F41.2, F43.2], and obesity $\left[\right.$ BMI $\geq 30 \mathrm{~kg} / \mathrm{m}^{2}$, E66.X]). Adjusted odds ratios (OR) and $95 \%$ CI were calculated for each variable included in the model. Descriptive statistics are presented for all other variables. All analyses were performed using STATA $^{\text {TM }} 11.2$ (StataCorp LP, College Station, TX, USA).

\section{Results}

After controlling for socioeconomic factors, patients age, sex, and comorbidities, we found that having surgery in a high-volume hospital was associated with a decreased risk of having revision TKA within 2 years of the index procedure. In summary, a total of $3.7 \%$ of primary TKAs were revised within 1 year (1667 of 44,238 TKAs) and 5.5\% were revised within 2 years (2.389 of 43,569 TKAs) (Table 4). The odds ratio for the 2-year revision was 1.6 (95\% CI, 1.4-2.0; $\mathrm{p}<0.001)$ for an annual hospital volume of 56 or fewer cases, 1.5 (95\% CI, 1.3-1.7; p < 0.001) for 57 to 93 cases, $1.2(95 \% \mathrm{CI}, 1.0-1.3 ; \mathrm{p}=0.039)$ for 94 to 144 cases, and 1.1 (95\% CI, $0.9-1.2 ; \mathrm{p}=0.319)$ for 145 to 251 cases compared with a hospital volume of 252 or more cases (Table 5). Thus, the risk of revision surgery after primary implantation was higher in hospitals that performed fewer than 145 TKAs per year

\section{Discussion}

The effect of hospital volume on revision rates after TKA has been reported in prior studies [4, 6, 8, 17, 18, 24]. The main drawbacks of previous studies are that they have been based on Medicare or nationwide inpatient samples and that they lack detailed information regarding clinically important characteristics. In our study, we were able to show that having a TKA in a high-volume hospital was associated with a decreased risk of having revision TKA within 2 years of the index surgery, even after controlling for clinical factors and for socioeconomic characteristics. The risk of revision surgery was higher in hospitals where less than 145 cases were performed per year.

The current study has some limitations. First, soft tissue disorders were noted only 31 days after index surgery. Second, we were not able to include the surgeon level as a confounding variable, which also might influence the failure rate. Third, the German insurance database does not provide cause of failure information. Fourth, owing to all small and large hospitals being grouped together, substantial amounts of local or granular data might be lost. 
Finally, although our study is based on nationwide data of the largest healthcare insurance provider in Germany, there may be variations in terms of age, sex, social status, and morbidity between patients insured by different German healthcare providers.

In 1998, Norton et al. [19] determined that hospital volume affected the in-hospital complication rate after knee replacement surgery. Interestingly, in their study, hospitals were defined as high-volume hospitals when more than 80 arthroplasties were performed per year. No uniform criteria are available to define high- and low-volume hospitals. However, hospitals that perform less than 100 arthroplasties per year have been defined as low-volume hospitals [16]. Laucis et al. [16] recently offered new definitions of high-volume and very high-volume centers, given that the annual number of total joint arthroplasties has dramatically increased in recent years. Their definition of low-volume hospitals $(<100$ cases per year) remained unchanged compared with definitions in previous reports. As expected, low-volume hospitals had the highest complication rate in their study [16]. In contrast, Pamilo et al. [20] estimated that smaller hospital volume was not a clear factor for revision surgery based on nationwide registry data of 59,696 knee replacements. Similar findings have been reported by others [5, 23]. Low-volume hospitals have been unambiguously associated with higher risk for revision surgery in UKAs [2, 3]. In England and Canada, some studies have shown hospital volume to be predictive of revision after TKA [10, 12, 21]. Manley et al. [17] reported on the positive effect of hospital volume on survival rate in a United States Medicare population; however, two limitations of their study must be noted. First, the definition of a low-volume hospital ( $\leq 25$ arthroplasties per year) was quite different compared with the definition in other studies. Second, the Medicare population does not include patients younger than 65 years.

The current study is the first to estimate the effect of hospital volume on revision rates in knee replacement surgery in Germany, We used data from a nationwide German insurance database of 45,165 TKAs and controlled for socioeconomic factors, patients age, sex, and comorbidities. In addition to the hospital volume, the following patientrelated characteristics were identified as independent risk factors for TKA revision within 2 years: lower age, male sex, obesity (BMI $\geq 40 \mathrm{~kg} / \mathrm{m}^{2}$ ), fluid and electrolyte disorders, chronic pulmonary disease, congestive heart failure, peripheral vascular disease, depression, neurologic disorders, and alcohol abuse.

Dy et al. [6] found younger age, male sex, depression, and chronic pulmonary disease as independent risk factors for TKA revision. While BMI was not a risk factor for revision surgery in their study, we did find that obesity with a BMI of $40 \mathrm{~kg} / \mathrm{m}^{2}$ or greater increased the risk of revision by $40 \%$. In contrast to our study, Dy et al. found the socioeconomic status to be an independent risk factor for revision surgery [6].

Based on the data analyzed, we found a clear association of higher risk for revision surgery when undergoing a TKA in a hospital performing less than 145 cases per year. Therefore, the study results could help practitioners to guide potential patients to hospitals with higher case numbers to reduce the overall revision and complication rate. In Germany, a minimum of 50 TKA cases per hospital per year are required to get permission to perform TKAs. We believe that this study underscores that the number of required TKA cases to perform a TKA should be a minimum of 145 cases per year. However, this needs to be balanced against issues of access to care in countries where geography and perhaps health-insurance concerns might preclude patients' abilities to travel to such centers. Furthermore, our study presents the patient-related risk factors that increase the risk for revision surgery. The management of those factors should be included in the routine protocol before performing a TKA.

\section{References}

1. AQUA. Institut für angewandte Qualitätsförderung und Forschung im Gesundheitswesen GmbH. Available at: https://www. aqua-institut.de. Accessed July 31, 2017.

2. Badawy M, Espehaug B, Indrekvam K, Havelin LI, Furnes O. Higher revision risk for unicompartmental knee arthroplasty in low-volume hospitals. Acta Orthop. 2014;85:342-347.

3. Baker P, Jameson S, Critchley R, Reed M, Gregg P, Deehan D. Center and surgeon volume influence the revision rate following unicondylar knee replacement: an analysis of 23,400 medial cemented unicondylar knee replacements. J Bone Joint Surg Am. 2013;95:702-709.

4. Bohm ER, Molodianovitsh K, Dragan A, Zhu N, Webster G, Masri B, Schemitsch E, Dunbar M. Outcomes of unilateral and bilateral total knee arthroplasty in 238,373 patients. Acta Orthop. 2016;87(suppl 1):24-30.

5. Bozic KJ, Maselli J, Pekow PS, Lindenauer PK, Vail TP, Auerbach AD. The influence of procedure volumes and standardization of care on quality and efficiency in total joint replacement surgery. J Bone Joint Surg Am. 2010;92:26432652.

6. Dy CJ, Marx RG, Bozic KJ, Pan TJ, Padgett DE, Lyman S. Risk factors for revision within 10 years of total knee arthroplasty. Clin Orthop Relat Res. 2014;472:1198-1207.

7. Elixhauser A, Steiner C, Harris DR, Coffey RM. Comorbidity measures for use with administrative data. Med Care. 1998;36:8-27.

8. Jasper LL, Jones CA, Mollins J, Pohar SL, Beaupre LA. Risk factors for revision of total knee arthroplasty: a scoping review. BMC Musculoskelet Disord. 2016;17:182.

9. Jeschke E, Gehrke T, Günster C, Hassenpflug J, Malzahn J, Niethard FU, Schräder P, Zacher J, Halder A. Five-year survival of 20,946 unicondylar knee replacements and patient risk factors for failure: an analysis of German insurance data. $J$ Bone Joint Surg Am. 2016;98:1691-1698.

10. Judge A, Chard J, Learmonth I, Dieppe P. The effects of surgical volumes and training centre status on outcomes following total 
joint replacement: analysis of the Hospital Episode Statistics for England. J Public Health (Oxf). 2006;28:116-124.

11. Katz JN, Mahomed NN, Baron JA, Barrett JA, Fossel AH, Creel AH, Wright J, Wright EA, Losina E. Association of hospital and surgeon procedure volume with patient-centered outcomes of total knee replacement in a population-based cohort of patients age 65 years and older. Arthritis Rheum. 2007;56:568-574.

12. Kreder HJ, Grosso P, Williams JI, Jaglal S, Axcell T, Wal EK, Stephen DJ. Provider volume and other predictors of outcome after total knee arthroplasty: a population study in Ontario. Can J Surg. 2003;46:15-22.

13. Kurtz S, Ong K, Lau E, Mowat F, Halpern M. Projections of primary and revision hip and knee arthroplasty in the United States from 2005 to 2030. J Bone Joint Surg Am. 2007;89:780-785.

14. Kurtz SM, Lau EC, Ong KL, Adler EM, Kolisek FR, Manley MT. Which hospital and clinical factors drive 30- and 90-day readmission after TKA? J Arthroplasty. 2016;31:2099-2107.

15. Kurtz SM, Ong KL, Lau E, Bozic KJ. Impact of the economic downturn on total joint replacement demand in the United States: updated projections to 2021. J Bone Joint Surg Am. 2014;96:624-630.

16. Laucis NC, Chowdhury M, Dasgupta A, Bhattacharyya T. Trend toward high-volume hospitals and the influence on complications in knee and hip arthroplasty. J Bone Joint Surg Am. 2016;98:707-712.

17. Manley M, Ong K, Lau E, Kurtz SM. Total knee arthroplasty survivorship in the United States Medicare population: effect of hospital and surgeon procedure volume. J Arthroplasty. 2009; 24:1061-1067.

18. Namba RS, Cafri G, Khatod M, Inacio MC, Brox TW, Paxton EW. Risk factors for total knee arthroplasty aseptic revision. $J$ Arthroplasty. 2013;28(8 suppl):122-127.

19. Norton EC, Garfinkel SA, McQuay LJ, Heck DA, Wright JG, Dittus R, Lubitz RM. The effect of hospital volume on the inhospital complication rate in knee replacement patients. Health Serv Res. 1998;33:1191-1210.
20. Pamilo KJ, Peltola M, Paloneva J, Makela K, Hakkinen U, Remes V. Hospital volume affects outcome after total knee arthroplasty. Acta Orthop. 2015;86:41-47.

21. Paterson JM, Williams JI, Kreder HJ, Mahomed NN, Gunraj N, Wang X, Laupacis A. Provider volumes and early outcomes of primary total joint replacement in Ontario. Can J Surg. 2010;53: 175-183.

22. Quan H, Sundararajan V, Halfon P, Fong A, Burnand B, Luthi JC. Coding algorithms for defining comorbidities in ICD-9-CM and ICD-10 administrative data. Med Care. 2005;43:1130-1139.

23. Shervin N, Rubash HE, Katz JN. Orthopaedic procedure volume and patient outcomes: a systematic literature review. Clin Orthop Relat Res. 2007;457:35-41.

24. Shin $\mathrm{CH}$, Chang $\mathrm{CB}$, Cho SH, Jeong JH, Kang SB. Factors associated with the incidence of revision total knee arthroplasty in Korea between 2007 and 2012: an analysis of the National Claim Registry. BMC Musculoskelet Disord. 2015;16:320.

25. Singh JA, Kwoh CK, Boudreau RM, Lee GC, Ibrahim SA. Hospital volume and surgical outcomes after elective hip/knee arthroplasty: a risk-adjusted analysis of a large regional database. Arthritis Rheum. 2011;63:2531-2539.

26. Solomon DH, Losina E, Baron JA, Fossel AH, Guadagnoli E, Lingard EA, Miner A, Phillips CB, Katz JN. Contribution of hospital characteristics to the volume-outcome relationship: dislocation and infection following total hip replacement surgery. Arthritis Rheum. 2002;46:2436-2444.

27. Soohoo NF, Zingmond DS, Lieberman JR, Ko CY. Primary total knee arthroplasty in California 1991 to 2001: does hospital volume affect outcomes? J Arthroplasty. 2006;21:199-205.

28. Tan SC, Chan YH, Chong HC, Chin PL, Yew A, Chia SL, Tay D, Lo NN, Yeo SJ. Association of surgeon factors with outcome scores after total knee arthroplasty. J Orthop Surg (Hong Kong). 2014;22:378-382. 